\title{
THE CREATION OF NEW TRADITIONS: DISCUSSION OF RELATIONSHIP BETWEEN ARCHITECTURAL RURAL PRACTICE AND LOCAL FEATURES' INHERITING FROM A HERITAGE CONSERVATION PERSPECTIVE
}

\author{
M. Tian ${ }^{\mathrm{a} *}, \mathrm{M}$. Sun $^{\mathrm{a}}$ \\ ${ }^{\text {a }}$ School of Architecture, Southeast University, Nanjing, China - (mechelle_mengxiao, thecoldjoke)@126.com
}

KEY WORDS: Heritage Conservation, Rural Practice, New Traditions, Construction Technology, Self-help Construction, Skill Training, Local Features

\begin{abstract}
:
The traditional features of Chinese villages are facing a crisis of discontinuity. In the meantime, there exists a problem in architectural heritage conservation that while preservation and renovation is being done, local self-help construction still proceeds out of control. Nowadays, an increasing number of architects have noticed these phenomena and participate in the evolution of villages carrying various architectural practices in the countryside, which has certain influence at the place, whether during or after the construction. In many well-evaluated rural practice cases in the world, architects not only choose appropriate materials and crafts for natives, but also renew local traditions by offering skill training to craftsmen. However, in Chinese villages, similar practices do not seem to be that effective. Therefore, through field research and interviews, this article discusses the reasons that relatively successful architectural practices in Chinese villages fail to exert a positive influence to the inheriting and update of local traditions. These causes include the increase of information sources, the different aesthetic manner, the conception differences, the influence of constructors, and the instructor role that architects play.
\end{abstract}

\section{INTRODUCTION}

Chinese villages have the characteristic of natural growth with an inherent logic in the process of development, which forms different regional, historical and cultural features. Recently, on one hand, as economy and construction increases, agrestic construction technology has gradually failed to meet social needs. On the other hand, the number of craftsmen reduces, traditional crafts face the crisis of discontinuity. In the meantime, there exists a problem in architectural heritage conservation that while preservation and renovation is being done, local self-help construction still proceeds out of control. Nowadays, an increasing number of architects have noticed these phenomena and get involved in the evolution of villages carrying various architectural practices in the countryside, which has certain influence at the place, whether during or after the construction.

In related well-evaluated cases all over the world, architects redevelop local building materials to provide innovative design with traditional features. Also, they accomplish building performance optimization compared with local ones through appropriate construction technology according to local economic and resources. Besides, local villagers participate in the construction process and receive guidance from architects in many influential practices.

Positive impact was brought by these considerations based on materials, performance and skill training in many overseas cases. Architects not only show respect to local building technology, make optimum choices for areas of scarcity and poverty, and help residents realize their simple desire for a better life through improved building crafts. The most notable point here is the skill training that architects offer local craftsmen, which makes improved traditional building technology inheritable so that the renewal of tradition is achieved. In this process, architects become the creator of new traditions. ${ }^{1}$

However, it is a significant problem that in Chinese villages, similar practices seem to have little effectiveness in the terms of tradition renewal. The influence that architects have on indigene was less than satisfactory, although these works won different levels of praise in the industry, with architects' attempt to inherit and develop the tradition in all respects, and their attempt to use their own professional knowledge to introduce optimized construction technology into rural areas and teach villagers. On the contrary, farmers do not give credit to these architectural works. Usually, with the continuous construction and renovation of rural self-establish buildings, their works gradually become the only ones with traditional features in those regions. Architects update the tradition from the perspective of their own, but fail to acquire wide local approval so as to make new traditions pass along.

This paper will focus the discussion on this specificity of Chinese architectural rural practice. Taking the forms of field research and interviews, the investigation will be from different points of view including construction technology innovation, local resident participation, current situation of local dwelling construction and attitude of native villagers and craftsmen to architectural practices. It will try to elaborate on the reasons why in Chinese villages, architects carried relatively successful practices but were unable to produce distinct positive influence to the inheritance and update of local traditions.

\footnotetext{
* Corresponding author

(1) For example, the practice of Hassan Fathy, the practice of Diébédo Francis Kéré, and the school in Cabo Delgado by Eike Roswag.
} 


\section{CASE STUDY}

\subsection{Zheshang Hope Primary School in Maoping, Leiyang, Hunan Province}

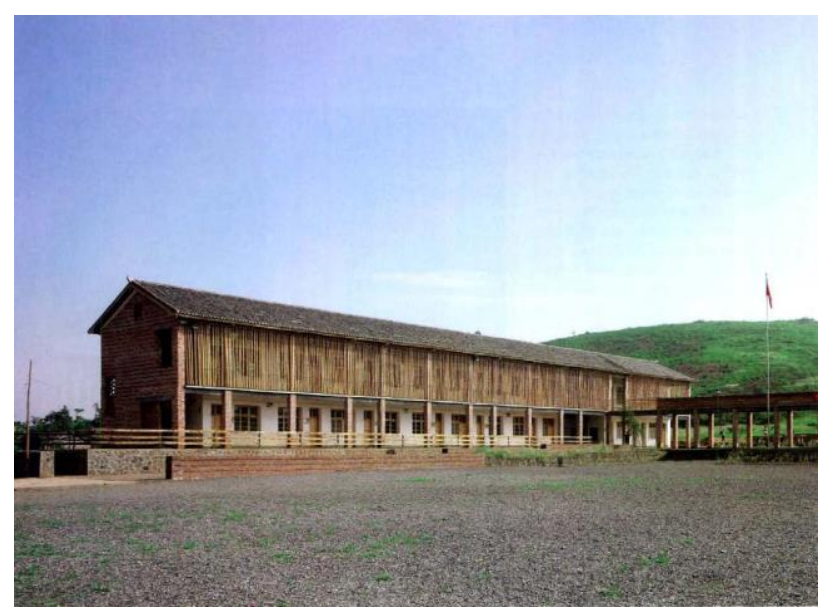

Figure 1. Full view of the school

(C) SPOT Image Copyright 2008, Christian Richters.

Established in Maoping of Leiyang in Hunan province in 2008, Zheshang Hope Primary School ${ }^{2}$ is a new Hope primary school that is raised the money by the chamber of commerce in Zhejiang and designed by In+of Architecture Firm after the flood destroyed the original primary school. The architects dwellings and it gives a response on the forms, materials and construction techniques (Wang, 2008). With blue roofing tile and double sloping roofs, the form and dimension of the primary school are basically close to long strips of townhouse in the village around the 1970s. Considering the construction cost and the local features, its wall materials continue to be the red brick.

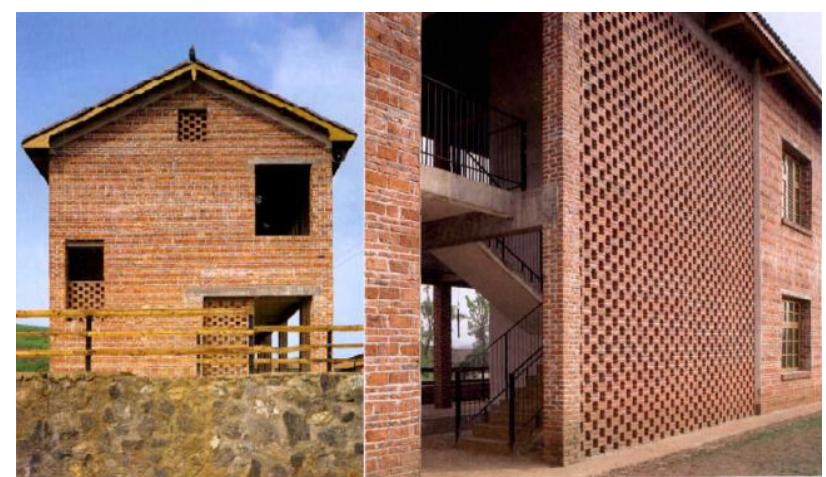

Figure 2. Lattice Wall in the gable facade and the atrium

(c) SPOT Image Copyright 2008, Christian Richters.

The design of the school satisfies the architects in three points: firstly, large-scale usage of hollowed-out lattice wall that appears in the resident's house (Figure 2). Secondly, the application of flat roof under the sloping roof after communicating with the local constructors. Thirdly, the facade of wooden grating that is the symbol of bamboo book and refers to local architectural language. These designs have made the performance advantage and kept the traditional style, "they

\footnotetext{
${ }^{(2)}$ Architects: In+of Architecture, Studio Wang Lu Completed:2008

Awards:

The $5^{\text {th }}$ Architectural Society of China Design Award of Merit, 2008.

The $3^{\text {rd }}$ International WA Community Awards, 2009.
}

harmonize with surrounding buildings and reflect its particularity as a teaching building and public building", and they have reached the architect's design goal: "the construction of the familiar and strange building for the natives".(Wang, 2008)

We firstly visited the Hope primary school in the field research that is built for about ten years. Its service condition is still good, and there are two aspects that are obviously different from the original appearance. Firstly, considering the safe problem, the holes in the bottom of the lattice wall in the north facade and the atrium were filled with the cement mortar, because the lively pupils like to climb up by standing on these holes. (Figure 3)

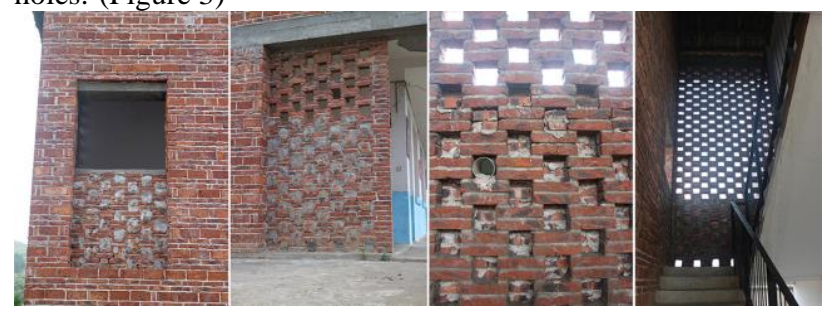

Figure 3. Filled Lattice Wall now

(Photography: M. Tian)

Secondly, the wooden handrail in the original entrance corridor of the first layer of the teaching building could not meet the safe requirements after the usage for a long time(now the entrance position has changed), so the villagers have used the strong metal handrail to change it in the school maintenance of the last year. The architects have the differences with the natives on the innovation of the traditional appearance design. The natives prefer affordable and firm buildings than the continuation of the traditional appearance.
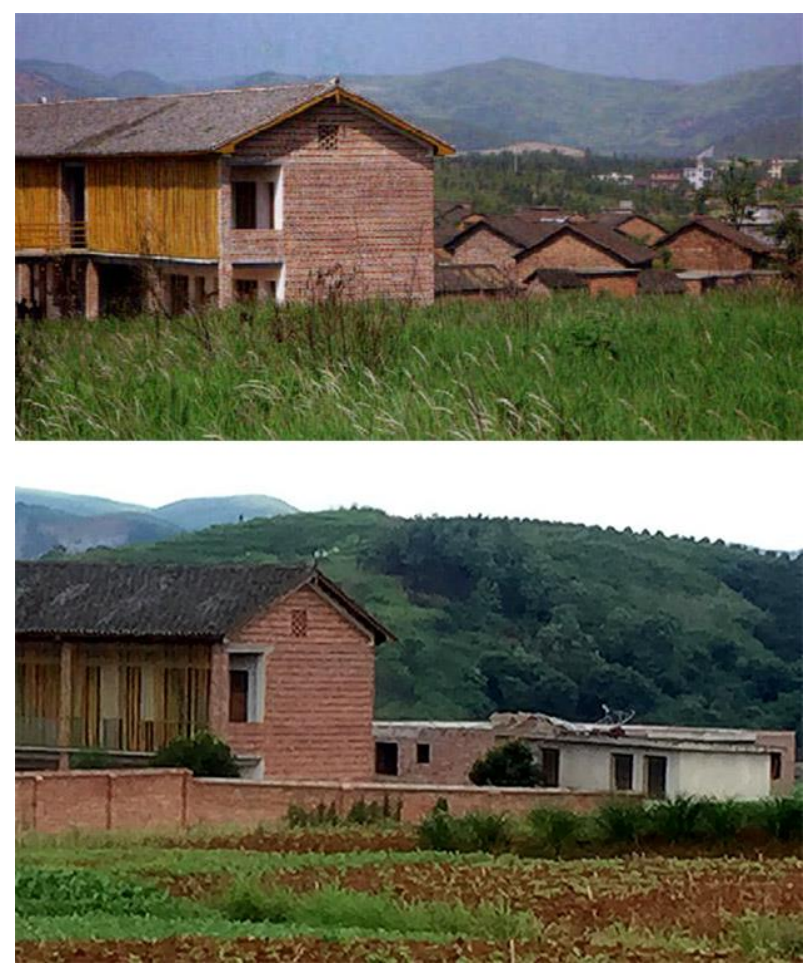

Figure 4. The past and the present

Upper: ( SPOT Image Copyright 2008, Christian Richters. Lower: photography: M. Tian 
Except for the building itself, the biggest difference is the great changes of the surroundings in the primary school, the characteristic houses with the red brick and grey tile have been torn down (Figure 4). It makes the primary school become the only building with a traditional image in this area that the architects have designed its form and style to continue the surrounding features and the village textures. The architects have inherited the tradition of the village, but the tradition has disappeared. Instead, now most of the newly-built or renovated buildings in Maoping have adopted the brick-concrete structure; they take the style of flat roof and two to three floors; the planar layout is also different from the original houses; the walls have used the tile facing or cement plaster. (Figure 5)

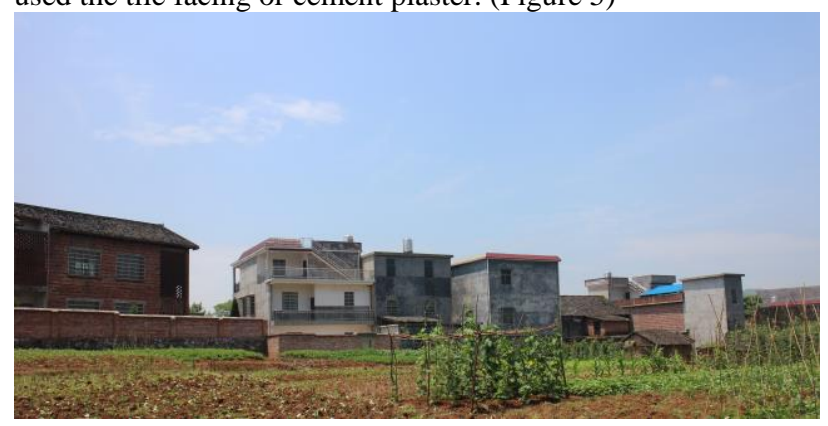

Figure 5. New houses right beside the school

(Photography: M. Tian)

Most of the remaining townhouse sin the 1970s have also been finished decoratively. Through the further talking, we learn about that the villagers think this kind of villa-style of "Foreignstyle Houses" is more popular. With the "beautiful and modern appearance", it has solved "the leakage problem of the tile roof in the old house", and its cement plaster can make the house "warm without the moist". The natives think the appearance and style of the Hope primary school "can be accepted", but they "won't use it to build houses because it is rustic".

We have found that the natives have their general distinction on the architectural style and the classification: "Indigenous House" and "Foreign-style House". For natives, the sloping roof is the typical feature of the Indigenous House, as the opposite of the trendy house, it represents the low waterproof performance, and it is unworthy of using continuously. For architects, the sloping roof is the reasonable form strategy to deal with the local natural environment and the traditional features. This reflects the differences between the architects and the local residents in aesthetic manner and expresses the divergence of two sides about whether should keep the local tradition.

In the end of the field research, we interviewed Tan Manyou in a local building site who has participated in the construction of the primary school. He said there were really many innovative designs in the school construction at that time, but these innovations were not used in the construction process of other residents in the village. Mr. Tan thinks the countrymen pay more attention to the effective cost in the construction process, they believe the flat roof can meet their needs of daily life, and "there is no need to add a sloping roof". In addition, the durability is very important, the lattice wall is beautiful and ventilative, but "it is not strong enough". These views express the countryman's simple pursuit of the building performance, and reflect that the countrymen always directly meet their actual demands within a certain budget when distributing the expenditure rather than put particular emphasis on the feature factors. This kind of practical psychology is also reflected in the architectural appearance under their aesthetic notions, because they only make the facing decoration in the facades that are often showed to the people rather than the hidden facades (Figure 6).

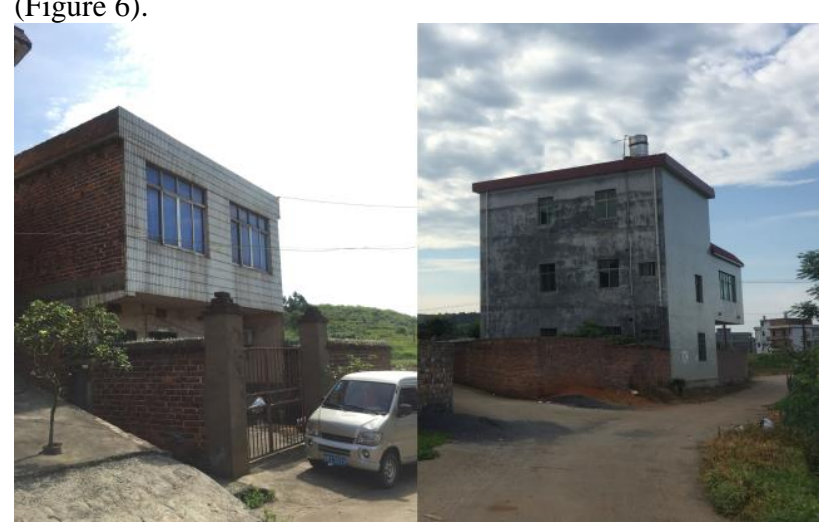

Figure 6. New houses with only showing facade decorated

(Photography: M. Tian)

Besides, during the interview, we find a large number of residential constructions are still under progress in the village. There are at least five houses being built, and most of the construction teams come from the outside of the village, only Mr. Tan's construction team has participated in the construction of the Hope primary school. And this kind of quick liquidity of the constructors also influences the spread of the architect's building strategy.

\subsection{Work Station of Baishuihe Nature Reserve, Sichuan Province}

In a series of practices of the lightweight construction system in Zhu Jingxiang's team, the influence of their construction process on the local buildings has been reflected. For example, the damp-proof effect of the high base in the traditional houses of Guangyuan in Sichuan province is very little because of the capillarity of the concrete, so Zhu Jingxiang's team has designed the new base structure in Xiasi primary school by their new technology. And the local craftsmen have gradually adopted or imitated these new things because of their excellent performance (Zhang, 2013a). There is an understanding in the design team: "the craftsmen in the village will naturally take the initiative to find the appropriate technology solution and cultural answer from the outside world when they have experienced the advantages and limitations of new houses, seen the improved classroom of architects, realized the sewage and other environmental problems" (Zhu, 2011). So the paper chooses the Work Station of Sichuan Baishuihe Nature Reserve, the fifth building in this series of practice, to make the field research.

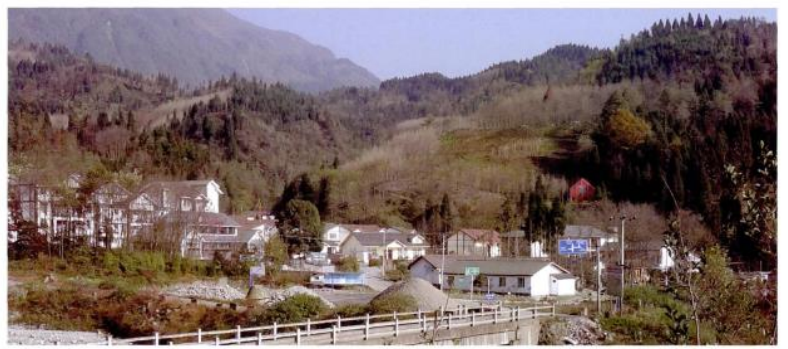

Figure 7. Distant view of the work station

(C) SPOT Image Copyright 2013, Zhang Dongguang. 


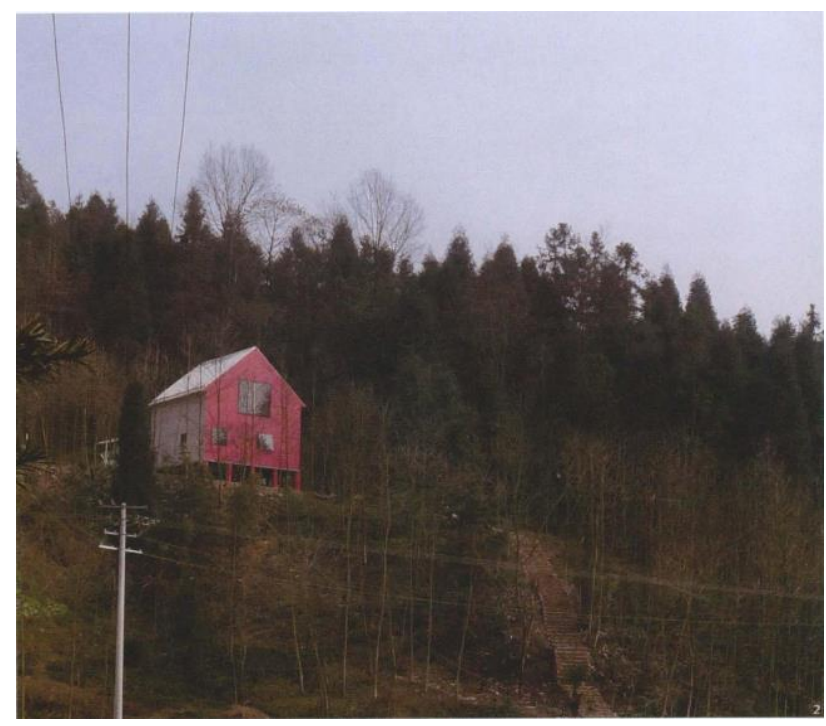

Figure 8. The work station

(C) SPOT Image Copyright 2013, Zhang Dongguang.

The reserve center is located in the mountainside and overlooks the village (Figure 7,8). The reason of the designer's site selection is most of the local traditional villages are built in the highlands to retain more flat lands and to avoid the flood, the heavy houses are built in the plains to occupy the farmland in recent years because of the industrial transformation, convenient traffic, quick reconstruction after the disaster and other factors. The architects think that the construction of the center in the mountain is a response to the tradition and is to look for the future meaning of the construction in the mountain, so the integration of cable car with the single track (originally used in the citrus picking) in the project has become the core of the design. The prospect of the exploitation around light cable car in the mountain areas is also conceived. (Zhang, 2013b)

The light-steel structure, wood-based panels and cement fibreboard in this project come from the outside market. They are introduced to the village as a whole of lightweight construction system. The assembly of the system is different from the construction of the traditional houses, so the architects guide the local workers to operate. (Figure 9)
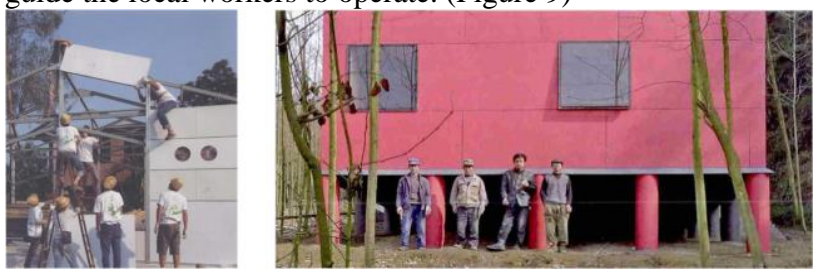

Figure 9. Left: the assembly of this lightweight building system in Xiasi project.

(C) SPOT Image Copyright 2013, Zhu Jingxiang.

Right: the constructor of Baishuihe project.

(C) SPOT Image Copyright 2013, Zhang Dongguang.

We find the construction is still in use in the visit, as its particularity makes it get the higher recognition from the villagers. But on the other hand, this house has become an isolated case, which no houses imitate in the selection of materials and site. In the conversation, although the foreman said that he did not acquire new knowledge in the house construction, it reflects his deep understanding of the construction system that he could talk eloquently about the composite wall structure, the difficulties in the transportation and component machining, the suspending base and the antiseismic property of the structure. It is notable that the foreman claims "the house is very firm because of its shaking; it can't fall down in the earthquake". These unusually organized words reveal the foreman's belief has come from the teaching of others, who could clearly only be the designers.

It shows that the workers have actually acquired the knowledge and skills to build this new system. But they did not use these skills in the subsequent construction, and the main reason is that the materials and plan in the reserve centre construction are provided by the architects, hence it is very difficult for them to obtain the new materials and the processed component products in accordance with the design drawing if they have disaffiliated from the architect's organization. In this case, the workers will still naturally continue to use the old construction way habitually.

\subsection{Activity Room For the Old of Nantang Cooperative, Fuyang, Anhui Province}

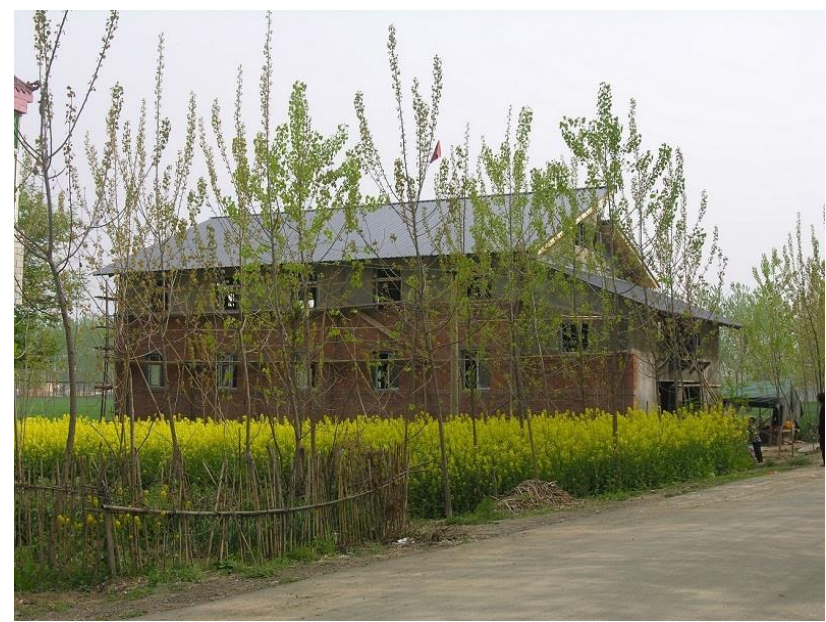

Figure 10. The Activity Room

(C) SPOT Image Copyright 2015, People's architect inc..

The Activity Room for the Old of Nantang Cooperative in Fuyang of Anhui province was built in 2007, and it is designed by Xie Yingjun's team in Taiwan and the Rural Architecture Studio for the old in the cooperative. With three floors, five bays, and the gable added the lateral slope, it covers 205 square meters. The body is light-steel structure, and the double sloping roofs have adopted the dark grey profiled steel sheet (Figure 10). The walls have used double bamboo weaving and the form of the straw inside and the plaster outside, as well as the wainscot of red bricks. The old men in the cooperative have raised the money and built it by themselves. Uniquely, their average age is over 60 (Atelier-3, 2007a), and they have successfully completed the construction process of building the frame and base, connecting the light steels, weaving of bamboo walls and bricklaying under the guidance of designers. (Atelier-3, 2007b) (Figure 11) 


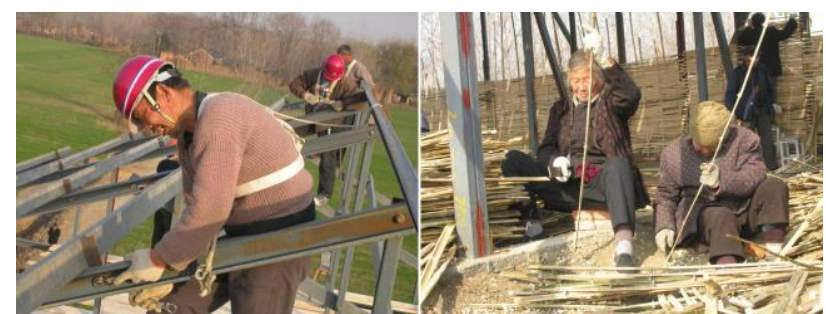

Figure 11. The construction by the old themselves

(C) SPOT Image Copyright 2015, People's architect inc..

Now the activity room is still the main arena for the old, and it also accommodates the stay-at-home children in the village to read books and play games. In recent years, the old men have raised some money to make the maintenance, such as the sliding door and window toward the balcony on the second floor, the handrail in the balcony, etc. The maintenance of light-steel keel structure system is good, but the wooden floor and lightweight partition walls have showed some damages with the increase of service life.

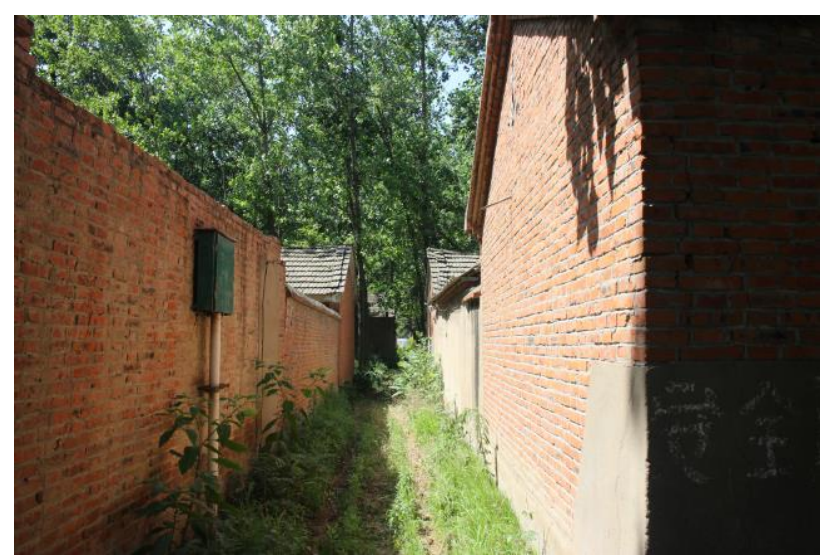

Figure 12. The abandoned old village

(Photography: M. Tian)

The village of the entertainment room has developed rapidly in the past two years. The old original houses with the red brick have been abandoned (Figure 12), and the new houses are the small Foreign-style Houses with three or four floors and colorful tiles. These new buildings are constructed along the road and clearly reflect certain kinds of template styles. Many houses have the similar appearances and mix the Chinese and western styles (Figure 13), such as the convex balcony supported by the golden chapiter (Figure 14).

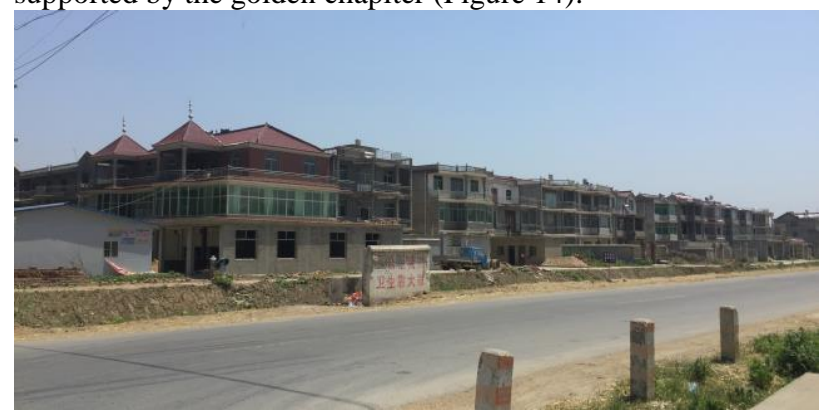

Figure 13. The similar new houses along the road

(Photography: M. Tian)

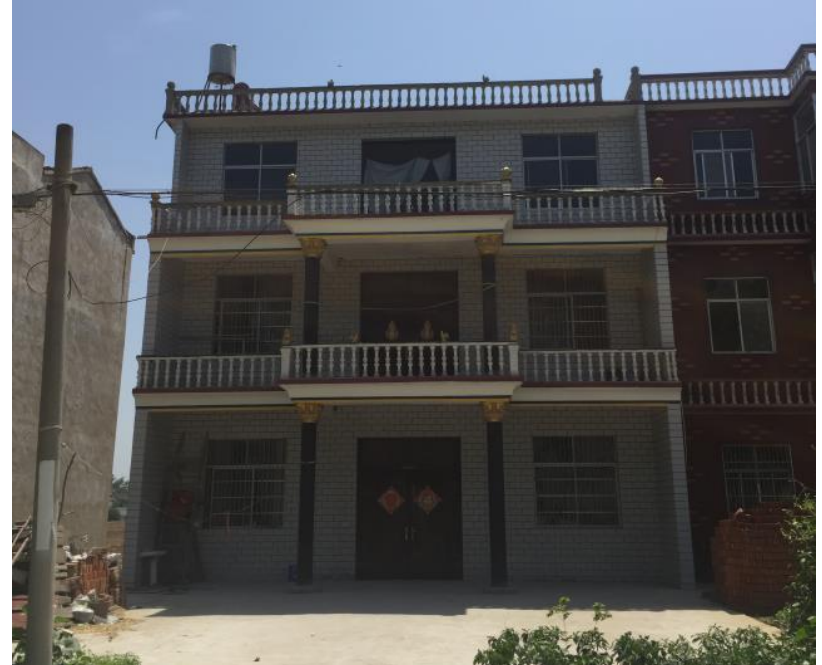

Figure 14. The golden chapiter

(Photography: M. Tian)

The new buildings have also adopted the model of living on the higher floor and business on the low floor, although there is no commercial activity now. Their site selection along the road reflects the influence of economic development and the increase of the convenient traffic on the village construction. The templated architectural form and its spread of the wide copy have also reflected the information complexity brought by the increase of urban and rural communication. In this circumstance, the style of grey roofs and white walls of the activity room looks very different.

It is lucky in the visit that we have interviewed Fan Guaiqing who has participated in its construction and now is the vice president of the senior association. We have learned that it is hard for them to build it by themselves and almost takes one year, but the cost is very low. Its cost per square meter is almost half of other buildings at that time, which has solved the shortage problem of self-financing. Meanwhile, the architects guided their construction on site. The steels were bought from the outside, and then they punched on them and fixed the bolt; the old men bought two cars of bamboos, chopped them into the comb and wove the bamboo wall. Mr. Fan thinks this kind of bamboo weaving and plaster walls is warm in winter and cool in summer. In the winter, the wind cannot come in because of the inside straw, "it is comfortable than the Foreign-style building". $\mathrm{He}$ also approves of this kind of light-steel structure and thinks its anti-seismic property is good, as "the earthquake place in Sichuan has also used it". But Mr. Fan and other villagers did not use the bamboo wall in their houses, because it is troublesome and needs too much time.

Now Mr. Fan lives in the "Foreign-style house" along the road with his son. He misses the old house with the red brick, but the old house has been bulldozed to plant the crops. He says that today's young people like this new style of houses. Its construction speed is quick, but it needs more cost, "many people's money is spent on their houses". This passage profoundly reflects the current situation of certain kind of houses that is popular in the local villages. Different from the architects, the countrymen do not pay attention to the harmony between every house and the site; they think the house is a kind of construction type that can be copied in a large number, and the house's quality is closely related to its style. (Figure 15) 


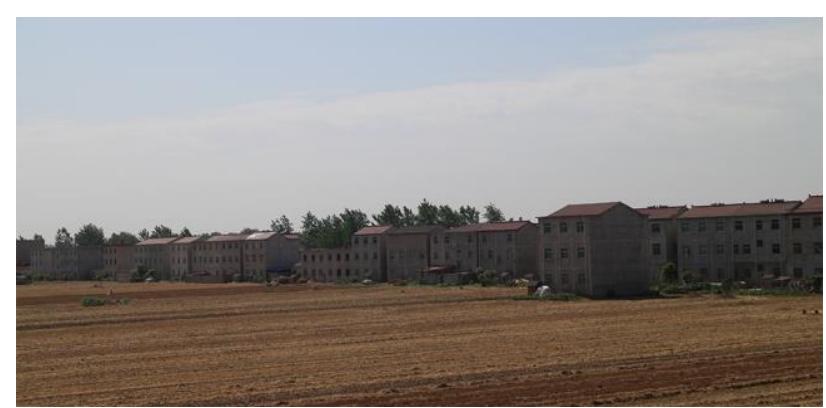

Figure 15. The similar new houses

(Photography: M. Tian)

At the same time, we can see that the architects have provided the new materials and technology in the construction of the senior centers, as well as the skills training. But it is different from other local houses that the activity center is built by the users in the actual process rather than the construction team, and it is not anxious to be completed quickly. Therefore, this technical way of the low efficiency and high cost-performance can be adopted. But for other houses, the long construction time means higher labor costs even if the material cost is low.

\section{ANALYSIS AND CONCLUSION}

As above, we make the investigation on the current situation of practical works, the construction views of the natives, their current construction ways and other aspects. In these cases, some put the emphasis on the usage of the traditional building materials and have completed the inheritance and update of the tradition in the form; Some focus on the building performance and have made the performance optimization of the traditional construction ways in the technology; Some pay attention to the skills training and emphasize the participation of the natives in the construction process. However, their common problem is that these attempts and innovations did not play very effective or positive role in the local construction, the architects and their works are still independent of the local self-help building process without creating the new tradition. For this common phenomenon, we have analysed the following reasons.

\subsection{Increase of Information Sources}

Many successful cases come from foreign areas with backward level of economic development, extremely harsh living conditions and inconvenient traffic, so that lack of information communication and their information sources are very single. So it is the best and unique solution of the natives that the architect makes the choice of technological innovation to meet their living needs for the purpose of dealing with the difficult environment. The architect's influence is especially strong in this circumstance.

With the development of urbanization, rapid improvement of rural economy and the increase of urban and rural communication in recent years, the amount of information has also been increased rapidly and the information sources have become various in China. At the same time, the choice range of materials and forms is also enlarged because of the convenient traffic and the developed network. Compared with the knowledge of the architect's work, the villagers are easier to be influenced by the outside information under this social condition. Therefore, the architect's influence has been weakened.

\subsection{Different Aesthetic Manner}

Urban life pattern has become the rural imitation object when the previous house, which relied on the craftsman skills, could not meet the living needs $(\mathrm{Li}, 2013)^{3}$. To some extent, the new style of the rural house has become a representative symbol of the ideal life style. Its architectural elements often come from different times or systems. Influenced by the psychological factor of "follow the fashion and mainstream", more villagers will tend to choose this kind of new house when some villagers have built the trendy patchwork of house. We often hear "It's very fashionable now" in the field research. Therefore, a spontaneous aesthetic manner of architectural appearance has been formed. It hinders architects to make the skills training for villagers that the new aesthetic manner has caused different recognitions between architects and villagers on the rural building practices and brought the passivity of knowledge learning. On the contrary, in some foreign cases, the natives actively learn the building skills from architects because of the weak outside influence. So their architects can successfully update the old tradition to become the shaper of new tradition.

In Chinese rural practice cases, the architects fully consider the original architectural materials, forms and other traditional elements to make the construction design for the purpose of inheriting the tradition, reservation and innovation. But the local villagers think these wooden beams, cob walls and tiled roofs should not continue to be used because they "look very rustic". It reflects the differences between architects and the natives on the rural society and construction. "The urbanites think some rural things are very interesting and hope to keep them, but the farmers think they are very backward rather than the special things and hope to change them as soon as possible." ( $\mathrm{Li}, 2013)$ Therefore, can it be called the tradition if it has only become the inherited tradition of architects and has disaffiliated from the users?

\subsection{Conception Differences}

The conception differences between architects and villagers embody in the architectural appearance, as well as the internal spatial and living experience. House has the profound meaning in Chinese rural culture. The house is the living place and the inherited property of the descendants, as well as the status symbol and the recognized position in the village. So the villagers think the house must be built even they have to borrow the money. The process of building the house is the architectural process and the expression of the rural social pattern. The house seems to be the face of the family, the bigger with more rooms, the better. In the certain economic conditions, many villagers think it is ok if the internal building performance can meet their basic daily demands, and they often pay more attention to its appearance. It can be seen that a lot of houses only have the elaborate painting and tile- -face on the external walls along the road, but their sides and rooms are often undecorated. In addition, the external decoration of many Foreign-style buildings is very complex, but their rooms still

\footnotetext{
${ }^{3}$ In the symposium, Mu Jun, one of the architects of Maosi Ecological Demonstration Primary School, Maosi Village, Qingyang, Gansu, said: 'In western villages lack of 'elite class', when traditional construction technology is not able to fulfil the increasingly diversified living demands, the only thing that villagers could do is to imitate the city mode that they see, understand and desire under the limited economic and technical condition."
} 
have the cement floor without the decoration or furniture. But the architects think the better internal comfort, the higher building performance and the better usage experience are not less important than the building appearance. However, it is difficult for residents to accept it immediately if it means more money. This custom culture has deepened the connotative complexity of the house because it's very obvious in Chinese countryside.

\subsection{Influence of Constructors}

As mentioned above, the previous Chinese buildings mainly depend on the craftsman's skills inheritance and memory transmission. Artisans have interacted with residents to bear the responsibilities from design to construction to overall management. Relied on the accumulation of experience and the transmission between masters and apprentices, this construction system is practical and flexible to promote the autonomous growth and development of the rural buildings. So the construction style in a place has a close relationship with its craftsmen. Relatively, architect is a later role, and construction team is even later than it. With the development of modern society and the division of work, the users generally do not participate in the construction. The construction team has also become an important one in its tri-game with the owner and the architect. The architect bears the responsibility of design and determination, while the construction team is responsible for the construction and plays the strong initiative in the situations ignored by the architect. With the development of urban overall construction, to a certain extent, it has caused the change of the rural social structure to collapse its traditional construction system of craftsmen that a large number of farmers gave up their traditional farming life to find job in the city. At present, a lot of rural self-establish buildings mainly rely on the construction team. The labor contractor often bears the overall command responsibility of the previous craftsman in the absence of architects. The construction team can master some normal practices and get the corresponding construction equipment and procurement channels by its construction experience in the cities. But the change of this construction system has also brought the new problems.

Firstly, the cognition and learning level of construction teams are uneven. Some construction teams have the comprehensive cognition on the urban construction because of their participation in the formal buildings and stronger learning ability. While some other construction teams have used the architectural elements of different areas in one building to make the strange architectural style because of their sciolistic knowledge. Secondly, the construction team can quickly complete the farmer's construction target to save the construction cost by relying on its experience of a certain kind of building style. In this way, with the flow of the construction team in different areas, the template of rural self-establish buildings can be formed and fashionable.

In the foreign cases, the style of self-establish buildings of the natives is still maintained. The architect can update their traditional building skills and train them to spread the better building strategy. But in the domestic cases, the number of construction teams that architects have trained cannot meet the local construction demands. We find that there are at least five new buildings that are being built in Maoping, but only one building is built by the constructors who have participated in building the Hope primary school.

\subsection{Architects as Instructors}

The construction team can maintain the basic and stable construction process and procurement channels in a large number of buildings. The architects have made the innovation in the materials and technology after entering the countryside, but they cannot ensure the construction team will use them in the future construction although their choice is accurate and suitable and is approved by the users. The previous craftsmen often used the local materials because it was easy to be obtained, and now the construction teams have mastered the stable and complete procurement channels. Compared with it, the architects can introduce the new materials and construction system by their abilities of getting resources, organizing the manpower and controlling the process. In this way, the effective time and capital plan can be made to control the cost within the reasonable range. But the access of these new materials is not fully provided to the natives in the skills training, and the natives also cannot learn these abilities well ${ }^{4}$. So they think this situation has increased their difficulty of obtaining new materials and the construction costs.

The farmers can always keep the learning attitude towards the new things, and the architects can become their important source of knowledge. They will try to imitate the urban pattern that they have seen, understood and desired rather than stop the learning process even if the architects have given up this responsibility. In the projects related to the research, the participation of the natives is only regarded as the choice that is beneficial to the project completion, while the skills training can be promoted to an equal position as important as the construction itself in the foreign cases. It is one of the reasons why the villagers do not express their practical skills in the subsequent construction after they have mastered a lot of fragmented knowledge.

\section{PROSPECTS AND SUGGESTIONS}

It can be seen that the complex conceptual and social problems are behind the particularity of the rural construction practices in China. In this circumstance, the architects should understand not only the local architectural features, but also the production and living mode, and the form of social organization if they want to actually join the rural self-help growth process to become the shaper of the new tradition. For architects, whether they should understand the tradition and the attitude toward the tradition of the farmers from the farmer's perspective, or should become the instructors in the local construction to make the training of building skills and protection awareness for the natives? These problems are worthy of being discussed further.

\footnotetext{
${ }^{4}$ Such abilities are the core competence of some design team, which cannot be open to the public. How to make these abilities available for serving the public is another issue worth studying.
} 


\section{REFERENCES}

Atelier-3, 2007a. Report on Nantang Cooperative, Fuyang, Anhui http://www.atelier-3.com.cn/index.php?id=63

Atelier-3, 2007b. Gallery of Collaborative Construction in China, Nantang Cooperative Project, Fuyang, Anhui http://www.atelier-

3.com/gallery2/main.php?g2_itemId=25936(04 Apr. 2008)

Diébédo Francis Kéré, 2013. Talk on an official TED conference: How to build with clay and community. http://www.ted.com/talks/diebedo_francis_kere_how_to_build_ with_clay_and_community (Sep. 2013)

Fathy H, 1973. Architecture for the Poor. The University of Chicago Press, London, UK.

Li H., 2013. Change and Rejuvenation: Symposium on Architectural Way to Deal with the Rural Change. Architectural Journal, 2013(12), pp. 004-009.

Lin N., 1992. Behind the Mysterious Veil: Evaluation of Egyptian Architect Hassan Fathy. World Architecture, 1992(6), pp. $67-72$

Lu J., 2009.Architectural Regionalism in Spontaneous Building.

Schittich C. (Editor-in-chief), 2012. School in Cabo Delgado. Architecture \& Detail, 10(4), pp. 552-556

Wang Lu, 2008. Maoping Zheshang Hope Primary School, Leiyang, Hunan. Architectural Journal, 2008(7), pp. 27-34.

Zhang D, 2013a. Plinth or Footing: The Strategies of Foundation Design in Applied Projects of Lightweight Building. Architectural Journal, 2014(1), pp. 101-105.

Zhang D, 2013b. Application of Light-weight Building System in Mountain Areas: Sichuan Baishuihe Nature Reserve Work Station with Monorail. Time+Architecture, 2013(5), pp. 112119.

Zhu J, 2011. The Formation of New Bud Schools. Time+Architecture, 2011(2), pp. 46-53. 